Archived version from NCDOCKS Institutional Repository http://libres.uncg.edu/ir/asu/

\title{
Appalachlyan
}

$\bar{B}$ O O N E, N O R T H A R O L N A

\section{Identifying Multivariate Vulnerability Of Nursing Home Facilities Throughout The Southeastern United States}

\author{
By: Matthew J. Wilson, Maggie M. Sugg, and Sandi J. Lane
}

\begin{abstract}
To identify nursing home vulnerability attributable to location using a triangulated approach that includes historic natural hazards, community vulnerability and nursing home attributes, we use an inductive-hierarchical vulnerability index construction model. Principal components analysis (PCA) is used for two inductive models of community (CLI) and natural hazard (HLI) vulnerability. Analytical hierarchy process (AHP) is used to determine weights, according to expert ranks, for a hierarchical model of nursing home facility level vulnerability (NHLI). These three sub-indices are combined using an equal weights hierarchical approach to create a multivariate nursing home vulnerability index (MNHVI). Hazard level vulnerability is predominantly attributable to storm surge, minor hurricanes, and inland flooding. Drivers of community level vulnerability were found to be poverty and minority population, age, income and housing, Hispanic population, family status, employment type and female gender, and nursing home population. Nursing home vulnerability is found to be higher for tracts and counties that house nursing home residents with decreased or limited mobility. The clusters throughout the study area that were identified as the most vulnerable for the MNHVI are predominantly attributable to their geographic location along the coastline. The mapped outputs can provide nursing homes with an easily distributable form of visual and quantitative information to share with emergency management agencies, family members or representatives of residents in nursing homes. This study can also assist administrators in risk assessment, development of policies and procedures, communication planning, and personnel training to comply with emergency preparedness regulations.
\end{abstract}

Matthew J. Wilson, Maggie M. Sugg, Sandi J. Lane (2019). Identifying multivariate vulnerability of nursing home facilities throughout the southeastern United States. International Journal of Disaster Risk Reduction, Vol. 36, May 2019, 101 106. https://doi.org/10.1016/i.ijdrr.2019.101106. Publisher version of record available at: http://www.sciencedirect.com/science/article/pii/S221242091831063X 


\title{
Identifying multivariate vulnerability of nursing home facilities throughout the southeastern United States
}

\author{
Matthew J. Wilsona,*, Maggie M. Sugga, Sandi J. Lane ${ }^{b}$ \\ ${ }^{a}$ Department of Geography and Planning, Appalachian State University, Boone, NC, United States \\ ${ }^{\mathrm{b}}$ Nutrition and Health Care Management, Appalachian State University, Boone, NC, United States
}

\begin{tabular}{ll} 
Keywords: & A B S T R A C T \\
\cline { 2 - 2 } $\begin{array}{l}\text { CMS datasets (MDS) } \\
\text { Factor analysis }\end{array}$ & To identify nursing home vulnerability attributable to location using a triangulated approach that includes \\
Hierarchical linear modeling & historic natural hazards, community vulnerability and nursing home attributes, we use an inductive-hierarchical \\
Long-term care & vulnerability index construction model. Principal components analysis (PCA) is used for two inductive models of \\
Natural disasters & community (CLI) and natural hazard (HLI) vulnerability. Analytical hierarchy process (AHP) is used to de- \\
Nursing homes & termine weights, according to expert ranks, for a hierarchical model of nursing home facility level vulnerability \\
Quantitative research methods & (NHLI). These three sub-indices are combined using an equal weights hierarchical approach to create a multi- \\
& variate nursing home vulnerability index (MNHVI). Hazard level vulnerability is predominantly attributable to \\
storm surge, minor hurricanes, and inland flooding. Drivers of community level vulnerability were found to be & poverty and minority population, age, income and housing, Hispanic population, family status, employment type \\
and female gender, and nursing home population. Nursing home vulnerability is found to be higher for tracts and \\
counties that house nursing home residents with decreased or limited mobility. The clusters throughout the \\
study area that were identified as the most vulnerable for the MNHVI are predominantly attributable to their \\
geographic location along the coastline. The mapped outputs can provide nursing homes with an easily dis- \\
tributable form of visual and quantitative information to share with emergency management agencies, family \\
members or representatives of residents in nursing homes. This study can also assist administrators in risk \\
assessment, development of policies and procedures, communication planning, and personnel training to comply \\
with emergency preparedness regulations.
\end{tabular}

\section{Introduction}

Over the last decade, there has been an increase in the number of billion-dollar weather disasters. In 2017, NOAA reported fifteen different billion-dollar natural disasters in the United States alone. This increase has resulted in a shift in disaster preparation methods, mitigation strategies, and emergency response programs [1,2]. Presently, healthcare facilities are required to be involved in collaborative preparation with their community partners using an all-hazards approach [3] and infrastructure situated in flood prone locations are required to purchase flood insurance [4]. In response to these disasters and policies, the hazards and vulnerability research fields have grown to address vulnerability to extreme weather events and disaster management policies in the U.S [5-9]. Findings from this research indicates that communities and their residents are vulnerable to a variety of natural hazards and some populations, including older adults, experience more harm than their younger peers $[6,10,11]$. Previous research has shown the need to geographically identify medically vulnerable older adult populations [12]. Nursing homes, and the older adult residents within them, are considered medically vulnerable and therefore more susceptible to the impacts of natural hazards [13-15]. In a study of postKatrina harm, 30 days post-Katrina, nursing home residents experienced an additional 277 deaths and 872 hospitalizations. At 90-days, 579 deaths and 544 additional hospitalizations were observed in this demographic [16]. Other studies found that almost one half of the deaths following Hurricane Katrina were adults aged 75 and older $[10,13]$, and $12 \%$ of the fatalities from Katrina and Rita combined were in nursing homes [10].

Natural hazards research has been a longstanding tradition in the field of geography that crosses the social and ecological divide. This inherent interdisciplinary approach to research provides an opportunity to investigate physical processes, human populations and demographics, social-ecological vulnerability, and the spatial distributions of these phenomenon $[6,7,9,16-22]$. Research on natural hazards

\footnotetext{
* Corresponding author.

E-mail address: wilsonmj2@appstate.edu (M.J. Wilson).
} 
combine literature from a multiplicity of social and natural sciences, health and human services, public safety, public policy, and information technology $[9,23]$. As more disciplines become involved in the social and physical responses to natural disasters, research approaches encompass more than only theoretical models and include approaches that emphasize the importance of the intersection of geophysical conditions, social systems, and vulnerable demographics such as nursing home residents and older adults [5,24,25].

Index creation studies have been used to identify vulnerability of various sorts critical, monetary, social, ecological, institutional, infrastructural, individual, and of communities [22,23]. Previous research has focused on the identification of a social systems vulnerability to specific natural hazards such as, hurricanes [6], flooding [17,22], and wildfire [26]. Considering vulnerability to specific hazards allows a more detailed analysis including specific caveats of that hazard. This is appropriate in some situations, but in other scenarios an understanding of vulnerability through an all hazards approach is necessary. Consequently, other studies have taken a multi-hazard approach to identifying vulnerability of social systems to multiple climatic and sociallysensitive hazards [17,19,27-29]; Shirley et al., 2012. The seminal work of Cutter et al. (2012) established the Social Vulnerability Index (SoVI), which has since become the most well-known index for vulnerability assessment at the sub-national level. The ability to quantitatively assign vulnerability measures make the SoVI a relatively simple method of visually and numerically conveying the complex underlying processes [30]. Due to higher concentrations of citizens living in areas considered at-risk for hazards (i.e., coastal and flood-prone riverine areas), understanding the social characteristics of these populations is becoming increasingly important for disaster risk management $[7,17]$. The SoVI uses the characteristics of social groups within a region to quantitatively determine their potential hazard vulnerability, preparedness, response, and recovery at a specific point in time [19].

Previous studies have identified older adults as being more vulnerable to natural disasters for many reasons, including post-disaster psychological stress, inability to comply with evacuation procedures, decreased cognitive abilities, limitations of mobility, vision/hearing impairments, and fewer economic resources, which can reduce willingness or ability to evacuate $[7,16,31]$. These frailties associated with physical and psychological impairments have been noted to increase the probability of death of nursing home residents during an evacuation. Post-hazard hospitalization and mortality can be observed with a lag period due to the increased physical and psychological vulnerabilities directly related to evacuation and indirectly related to the hazard occurrence [16]. Despite the risk of evacuating this demographic, post Hurricane Katrina public policy, requires evacuation for these at-risk facilities. Few studies, however, have examined the spatial and institutional vulnerability of nursing homes in relation to social and natural hazard vulnerability, which is an important first step in allocating resources and increasing public awareness. This study identifies the vulnerability of each nursing home according to its spatial location in reference to historic natural hazard occurrences, surrounding community characteristics, facility demographics, staffing, and resident quality indicators aggregated to the facility, census tract, and county levels.

\subsection{Conceptual framework}

To accurately conceptualize vulnerability according to natural hazard frequency, community characteristics, and nursing home data; three conceptual frameworks outlined by Fussel [56] were considered. Initially, a deterministic conceptualization was used for a Hazards Level Index containing variables that consider the frequency of natural disasters for census units since natural hazards cannot be avoided by human development and progress and are therefore unavoidable. A socio-ecological framework was employed for a Community Level Index, which contains United States Census variables at two scales of analysis (i.e. County and Census Tract) and the Nursing Home Level Index, which considers variables relating nursing home residents and facilities. A socio-ecological framework was employed for the CLI and NHLI. The socio-ecological concept was most appropriate for these indices since they both consider human behavior, perception, and physical/social conditions. The theory behind the MNHVI considers a mechanistic approach to vulnerability research where the implementation of technological advancements is believed to assist in the reduction of vulnerability. The only conceptual approach outlined in Fussel [56] which is not considered in this article is the political/economical approach, known as the structural theory. This structural theory considers the ideology that political structure influences vulnerability more than nature, technology, or society. The researchers determined this approach to be outside the scope of this analysis and instead emphasized the deterministic, the socio-ecological, and the mechanistic frameworks.

\subsection{Data and methods}

The study area is composed of ten states within the southeastern United States: Alabama, Florida, Georgia, Kentucky, Mississippi, North Carolina, South Carolina, Tennessee, Virginia, and West Virginia. The study area was selected due to the proximity to the gulf and atlantic coasts, where tropical cyclone and other extreme weather events are common (e.g., tornadoes, flash flooding, etc.).

Data were collected at the nursing home facility level $(n=2824)$ and census tract level $(n=16,284)$ to assess fine-scale patterns of vulnerability. Map outputs were aggregated to the county level $(n=924)$ to aid visual interpretation when necessary.

Previous vulnerability index research uses one of three structural approaches deductive, hierarchical, and inductive to quantitatively identify vulnerability [30]. The inductive approach has historically been the most commonly used (e.g. Refs. [12,32,33]; and was employed for the Community Level Index (CLI), the Hazard Level Index (HLI), and as a baseline comparison for the Nursing Home Level Index (NHLI).

The NHLI measured the inherent vulnerability of the institutionalized population and the resources available to support the residents (i.e., staffing and organization type) at the facility and census tract levels. The HLI, CLI, and NHLI, were created using 15 natural hazard variables for the HLI (Table 1), 23 socio-economic variables (Table 1), as recommended by the Cutters SoVI model, for the CLI, and 20 variables for the NHLI (Table 1). Data sources for the HLI include the Homeland Infrastructure Foundation Level Database (HIFLD), the National Oceanic and Atmospheric Administration (NOAA), and the Federal Emergency Management Agency (FEMA). For HLI data, which were not initially aggregated to the county or tract levels, a spatial join calculated the frequency of events (i.e., number of tornadoes experienced by each census tract) for each administrative unit. The SLOSH model, which is represented as a raster data set, was converted to vector data by calculating percentage of the area the census unit (tract or county) intersecting with the SLOSH polygons. All spatial analysis was conducted in ArcMap 10.6 [34].

Data sources for the CLI included the U.S. Census 2015 American Community Survey (ACS) 5-year estimates and the 2010 U S. Census, and variables were selected according to the SoVI model [35]. NHLI variables were selected from the Centers for Medicare \& Medicaid Services, Nursing Home Compare Minimum Data Set (MDS), which provides an assessment of functional, emotional, cognitive, and disease status for all long-term residents (i.e. residents who have stayed in the nursing home for 100 days or more) within each institution. As well as the public use staffing files and type of ownership (i.e., Staffing and Organization Medicare \& Medicaid Services, Nursing Home Compare data sets). Appropriate vaccinations denote the facility includes preventive measures in the care provided as an indication of the quality of care. Staffing hours and organization type have been associated with quality of care and resident outcomes (ie. lower staffing hours and for- 
Table 1

Indicator Sets for each Sub-Index.

\begin{tabular}{|c|c|c|}
\hline Sub-index & Variables & \\
\hline \multirow[t]{3}{*}{ Hazard LevelIndex (HLI) } & Historic Tornado Tracks (1851-2013) & Category 1-3 Hurricane Tracks (1851-2005) \\
\hline & Tropical Storm Tracks (1851-2005) & Category 4-5 Hurricane Tracks (1851-2005) \\
\hline & Tropical Depression Tracks (1851-2005) & Storm Surge (2017 SLOSH MOM Model) \\
\hline \multirow[t]{12}{*}{ Community Level Index (CLI) } & Median age & $\%$ households receiving Social Security benefits \\
\hline & Median gross rent & $\%$ ESL population \\
\hline & Median dollar value of owner-occupied housing & $\%$ employed in extractive industries \\
\hline & Per capita income & $\%$ children living in married couple families \\
\hline & Average people per household & $\%$ female \\
\hline & $\%$ of each nationality & $\%$ female headed households \\
\hline & $\%$ Hispanic & $\%$ population living in mobile homes \\
\hline & $\%$ unemployed & $\%$ housing units with no car \\
\hline & $\%$ population over 25 with under 12 year education & $\%$ families earning $\$ 200,000+$ peryear \\
\hline & $\%$ population in poverty & $\%$ employed in service industries \\
\hline & $\%$ renter occupied housing units & $\%$ population living in nursing homes \\
\hline & $\%$ unoccupied housing units & \\
\hline \multirow[t]{9}{*}{ Nursing Home Level Index (NHLI) } & $\begin{array}{l}\% \text { of long-stay residents whose need for help with daily } \\
\text { activities has increased }\end{array}$ & $\%$ of long-stay residents experiencing one or more falls with major injury \\
\hline & $\begin{array}{l}\% \text { of long-stay residents who self-report moderate to severe } \\
\text { pain }\end{array}$ & $\begin{array}{l}\% \text { of long-stay residents assessed and appropriately given the seasonal } \\
\text { influenza vaccine }\end{array}$ \\
\hline & $\%$ of high risk long-stay residents with pressure ulcers & $\begin{array}{l}\% \text { of long-stay residents assessed and appropriately given the } \\
\text { pneumococcal vaccine }\end{array}$ \\
\hline & $\%$ of long-stay residents who lose too much weight & $\%$ of long-stay residents who received an antipsychotic medication \\
\hline & $\begin{array}{l}\% \text { of low risk long-stay residents who lose control of their } \\
\text { bowels or bladder }\end{array}$ & $\%$ of long-stay residents whose ability to move independently worsened \\
\hline & $\begin{array}{l}\% \text { of long-stay residents with a catheter inserted and left in their } \\
\text { bladder }\end{array}$ & $\%$ of long-stay residents who received anti-anxiety or hypnotic medication \\
\hline & $\%$ of long-stay residents with a urinary tract infection & Staffing hours per resident per day (CAN, LPN, RN, Total staffing) \\
\hline & $\%$ of long-stay residents who have depressive symptoms & Organization type (For-profit, governmental, non-profit) \\
\hline & $\%$ of long-stay resident who were physically restrained & \\
\hline
\end{tabular}

profit ownership have been linked to poorer quality of care) [36-38]. Staffing hours available in the CMS public use data are registered nurses (RN) licensed practice nurses (LPN) and certified nursing assistants (CNA); physician extenders are not in this data set.

All variables for each subindex were analyzed using Principal Components Analysis (PCA) to reduce multicollinearity within the data. Data were normalized using z-score standardization and Pearson's correlation was used to assess correlation between variables. A KMO \& Bartlett's test of sphericity was implemented to quantitatively establish which variables were suitable for use within a component [39]. Upon completing the Pearson's correlation, factor analysis allowed examination into which variables, and subsequent factor components, were responsible for the largest proportion of variance.

To assist in interpreting variable impact for component selection, a varimax rotation was implemented to assess which variable explains the highest portion of variance within each component [33]. Components were selected according to the Kaiser criterion rather than parallel analysis, which removed components related to nursing homes $[33,40]$.

Analytical hierarchy process (AHP) was used for the NHLI to address concerns pertaining to the validity of factor selection from the NHLI PCA [41-43]. AHP allowed for an expert choice weighting scheme to be created for the 20 individual NHLI variables that could be combined in a hierarchical design. A convenience sample of experts who have/had worked in long-term care facilities in either research or occupational capacities ranked the nursing home variables (e.g., administrator, regional vice president).

All individuals hold/held positions of leadership in this field. There were five total experts chosen for this portion of the analysis. Each expert was emailed the list of variables with the instructions to rank them on their criticality (9 being most critical, 1 being least critical) during a disaster and the facility's evacuation or shelter in place. The results from the survey were averaged to determine the importance of each variable and a pairwise comparison matrix was used to evaluate each variable compared to one another (Saaty 1980). The largest eigenvalue in the comparison matrix is isolated and placed into the Consistency Index $(\mathrm{CI})$ formula where $\mathrm{P}=$ the largest eigenvalue and $\mathrm{n}=$ the size of the matrix:

$\mathrm{CI}=(\mathrm{P}-\mathrm{n}) /(\mathrm{n}-1)$

The CI value is then compared to the Random Consistency Index (RI) value which is given by Saaty (1980) to determine if the weights calculated are appropriate. This process is completed by calculating the Consistency Ratio (CR):

$\mathrm{CR}=\mathrm{CI} / \mathrm{RI}$

If the $C R$ value is found to be $<0.1$ then the variable weights which were calculated from the comparison matrix are considered appropriate and can be confidently implemented. Results from both NHLI outputs (PCA and AHP) were compared to the existing literature on organizational theory $[44,45]$ to determine which output was more appropriate to be retained for the final index.

The resultant indices created from the two inductive designs (e.g., CLI, HLI) were combined with the hierarchical AHP index (NHLI) using a equal weights hierarchical approach to create a final multivariate nursing home vulnerability index (MNHVI) (Fig. 1). All index scores were standardized before combination for the MNHVI. The hierarchical approach provides well-defined theoretical organization and reduced statistical complexity compared to the inductive approach $[5,46]$. The three indices were weighted according to the recommended equal weights aggregation scheme $[30,33]$. This inductive-hierarchical approach to a vulnerability assessment allows for a statistically robust factor selection through the inductive approach while retaining an organized theoretical design implicit in the hierarchical approach. The multivariate nursing home vulnerability index displays, both visually and quantitatively, the locations found to be most at-risk to natural disasters, socioeconomic conditions, and institution level factors. To determine the correlation and clustering of each value with itself across 


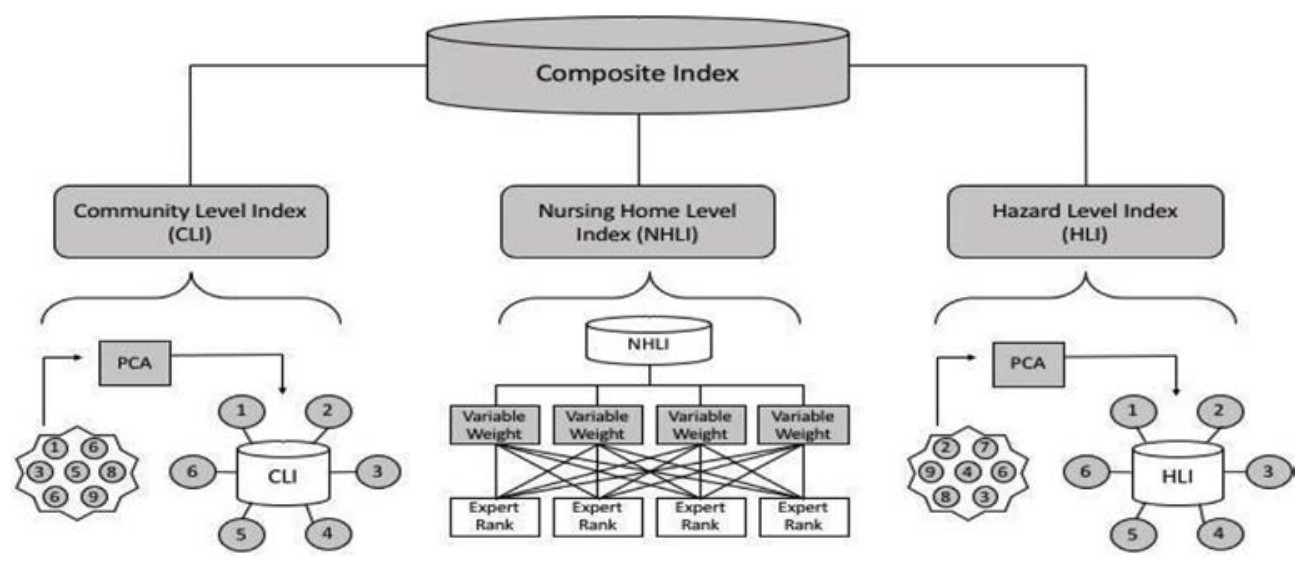

Fig. 1. Inductive-hierarchical model.

the study area, Global Moran's I and Anselin Local Moran's I were employed to test for spatial autocorrelation.

\section{Results}

\subsection{Hazard Level Index (HLI)}

The HLI included 15 natural hazard variables and after the PCA yielded 2 components that collectively explained $65.06 \%$ of the total variance (Table 2). The two components were named according to the variables with the highest loading values within each factor. Component 1 was titled Storm Surge $(43.77 \%)$ and component 2 was titled Minor Hurricanes and Flooding (21.29\%).

As expected, the majority of the Very High and High vulnerable tracts are along the coast where potential for hurricanes and storm surge is most concentrated (Fig. 2). Inland regions classified with above average vulnerability were due to inland flood zones from the NFHL. This can be observed by examining the number of Very High vulnerable tracts along the eastern coast of the Mississippi River. The proximity to the Mississippi River will not increase the possibility for storm surge in these tracts, however, it is expected to increase the size and amount of flood zones, which is accounted for in component 2, Minor Hurricanes and Flooding.

\subsection{Community Level Index (CLI)}

The CLI PCA produced 7 components (Table 3). These components collectively explained $71.6 \%$ of the total variance. The factors were named according to the variables which produced the highest loading values within each component. Components were named Poverty and Minority Population (25.3\%), Age (16.9\%), Income and Housing (9.8\%), Hispanic Population (6.6\%), Family Status (4.9\%), Employment and Female Population (4.4\%), and Nursing Facility Population (3.75\%).

The geographic pattern of the CLI at the census tract scale is displayed in Fig. 3 and is driven by components with high rates of relative poverty and minority populations. Due to the fine spatial scale of census tracts within the larger study area, the distribution and clustering of

Table 2

Hazard level index (HLI) PCA results.

\begin{tabular}{lll}
\hline Component & 1 & 2 \\
\hline Title & Storm Surge & Minor Hurricanes and Flooding \\
\hline $\begin{array}{l}\text { Percent Variance } \\
\begin{array}{l}\text { Eigenvalue } \\
\text { Top Loading Variables }\end{array}\end{array}$ & $43.77 \%$ & $21.29 \%$ \\
& SLOSH Model & 2.341 \\
& & Category 1-3 Hurricane Tracks \\
\hline
\end{tabular}

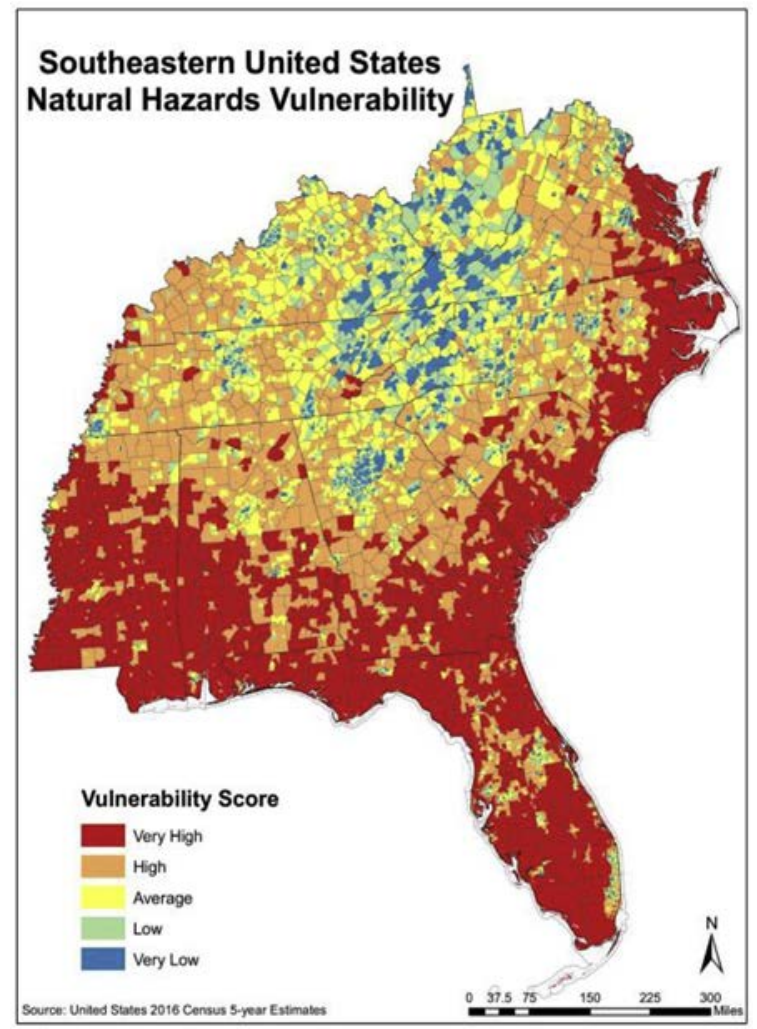

Fig. 2. Hazards Level Index created through a Principal Components Analysis at the Census Tract scale for the Southeastern United States.

vulnerability within high population density regions is difficult to identify. However, tests of spatial autocorrelation with Global Morans I show significant clustering of vulnerability $(p<0.001)$. Anselin Local Morans I tests of local spatial autocorrelation show significant clustering of vulnerability $(p<0.05)$ for $87.4 \%$ of the census tracts within the study area. Urban tracts were found to be highly clustered.

\subsection{Nursing Home Level Index (NHLI)}

The NHLI began with 20 variables at the nursing home facility and resident levels, and resulted in 7 components (Table 4). These components collectively explained $55.45 \%$ of the total variance. The factors were named according to the variables which produced the highest loading values within each component. Components were named Staffing (13.69\%), Vaccines (9.36\%), Mobility (8.96\%), Inappropriate Use of Medication (6.88\%), Residents with Urinary Tract Infections 
Table 3

Community level index (CLI) PCA results.

\begin{tabular}{|c|c|c|c|c|c|c|c|}
\hline Component & 1 & 2 & 3 & 4 & 5 & 6 & 7 \\
\hline Title & $\begin{array}{l}\text { Poverty and Minority } \\
\text { Population }\end{array}$ & Age & Income and Housing & $\begin{array}{l}\text { Hispanic } \\
\text { Population }\end{array}$ & Family Status & $\begin{array}{l}\text { Employment and Female } \\
\text { Population }\end{array}$ & $\begin{array}{l}\text { Nursing Facility } \\
\text { Population }\end{array}$ \\
\hline Percent Variance & $25.3 \%$ & $16.9 \%$ & $9.8 \%$ & $6.6 \%$ & $4.9 \%$ & $4.4 \%$ & $3.75 \%$ \\
\hline Eigenvalue & 6.84 & 4.56 & 2.65 & 1.79 & 1.32 & 1.19 & 1.01 \\
\hline $\begin{array}{l}\text { Top Loading } \\
\text { Variables }\end{array}$ & $\begin{array}{l}\% \text { population in } \\
\text { poverty, } \% \text { non-white } \\
\text { population }\end{array}$ & Median Age & $\begin{array}{l}\text { Per capita income, } \\
\text { Median dollar value } \\
\text { of housing }\end{array}$ & $\begin{array}{l}\% \text { Hispanic, } \% \\
\text { ESL population }\end{array}$ & $\begin{array}{l}\% \text { children in } \\
\text { married couple } \\
\text { families }\end{array}$ & $\begin{array}{l}\% \text { unemployed, \% female, } \\
\% \text { female headed } \\
\text { households }\end{array}$ & $\begin{array}{l}\% \text { population living } \\
\text { in nursing homes }\end{array}$ \\
\hline
\end{tabular}

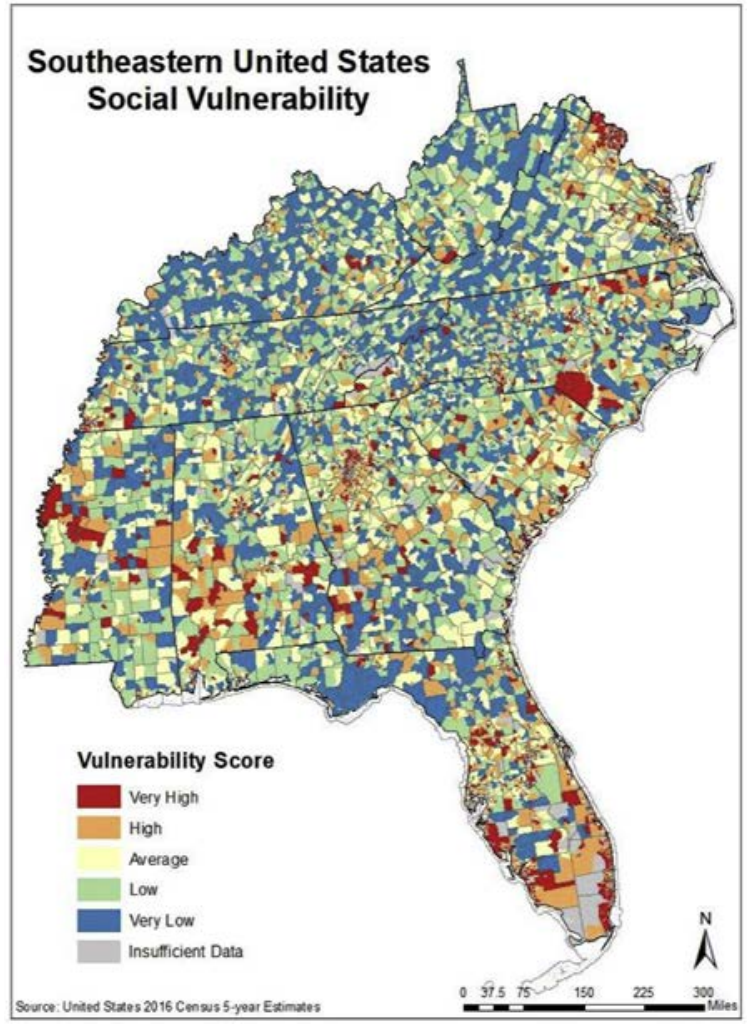

Fig. 3. Community Level Index - created using a Principal Components Analysis. Both figures are created at the Census Tract scale for the Southeastern United States.

(UTIs) (5.91\%), Residents with Ulcers (5.63\%), and Residents with Depressive Symptoms (5.02\%).

The geographic pattern of the NHLI at the census tract scale is displayed in Fig. 4a. However, only $15.9 \%$ of all census tracts within the southeast contain at least 1 nursing home. The fine spatial scale of census tracts within the larger study area, in addition to the small number of tracts containing nursing homes, makes visually representing spatial distribution of vulnerability at this scale dfficult. To overcome this limitation, the NHLI vulnerability scores were aggregated to the county level according to the average NHLI vulnerability score of tracts within each county (Fig. 4b).

The results from the NHLI PCA seemed questionable for the purposes of this study. While staffing, vaccines, and medication are certainly key factors to determining vulnerability of individual residents and facilities, these factors may not play as vital a role in vulnerability to shelter-in-place or evacuation scenarios following a natural disaster as the PCA suggests. To address this concern, AHP with expert choice rankings was implemented, according to existing organizational theory literature, to identify a weighting scheme for the 20 individual variables. Table 5 displays the average rank ascribed to each variable $(9$ being most critical, 1 being least critical) as well as the resultant weight from the AHP. Fig. 5a and $b$ displays the NHLI vulnerability scores at the census tract and county level, respectively.

The relative importance of each variable shifted significantly between the PCA and the AHP methods. While variables associated with staffing were determined to explain the highest proportion of variance from the PCA results, the AHP method displays that staffing related variables should only be weighted at $5.66 \%$. Whereas the AHP weighting scheme showed mobility related variables (Percentage of long-stay residents whose need for help with daily activities has increased and Percentage of long-stay residents whose ability to move independently worsened) should be calculated with the highest weights (9.66\% and $8.90 \%$, respectively). By changing from the PCA to the AHP method, the NHLI emphasizes the conditions of residents and de-emphasizes staffing.

\subsection{Multivariate nursing home vulnerability index (MNHVI)}

The standardized index scores from the CLI, HLI, and NHLI were combined at the census tract level in an equal weights hierarchical model. The multivariate vulnerability index was produced at the census tract and county levels (Fig. 6a and b). The equal weighting scheme for the three index scores was chosen due to a lack of objective reasoning for an unequal weighting scheme [33]. Tests of autocorrelation through Global Morans I show significant clustering $(\mathrm{p}<0.001)$. The majority of the highly vulnerable locations for the study area are clustered along the coastal tracts and counties, indicating that vulnerability is oftentimes attributable to geographic location of facilities.

At the census tract level, $11.92 \%$ of nursing homes are located with the Very Low vulnerability class, $15.28 \%$ are within tracts classified as Low vulnerability, $17.91 \%$ within the Average class, $24.99 \%$ within the High class, and $29.89 \%$ are within the Very High class. However, when aggregated to the county level, these percentages change significantly. At the county level, $13.33 \%$ of nursing homes are within counties classified as Very Low, $19.38 \%$ within the Low class, $18.07 \%$ within the Average class, $21.79 \%$ within the High class, and $27.27 \%$ within the Very High vulnerability class.

\section{Discussion}

This study identifies nursing home vulnerability attributable to location using a triangulated approach that included natural hazards, community vulnerability and nursing home attributes. Vulnerability reduction is a core element of managing disaster risk and has been identified as the most important prerequisite for minimizing the destruction of physical structures and harm to their inhabitants $[47,48]$. Vulnerability within the U.S. disproportionately falls on older adults, who often experience the largest number of deaths and injuries during and after natural disasters [31]. A recent example of harm to this demographic, incurred by natural hazards, was in the aftermath of Hurricane Irma where 14 nursing home residents died when their facility lost power and air conditioning [49]. As a response to this disproportionate harm, healthcare facilities, including nursing homes, are now 


\begin{tabular}{|c|c|c|c|c|c|c|c|}
\hline Component & 1 & 2 & 3 & 4 & 5 & 6 & 7 \\
\hline Title & Staffing & Vaccines & Mobility & Inappropriate Use of Medication & Residents with UTIs & Residents with Ulcers & $\begin{array}{l}\text { Residents with Depressive } \\
\text { Symptoms }\end{array}$ \\
\hline Percent Variance & $13.69 \%$ & $9.36 \%$ & $8.96 \%$ & $6.88 \%$ & $5.91 \%$ & $5.63 \%$ & $5.02 \%$ \\
\hline Eigenvalue & 2.738 & 1.871 & 1.792 & 1.377 & 1.183 & 1.126 & 1.003 \\
\hline Top Loading Variable & $\begin{array}{l}\text { Staffing per } \\
\text { resident per day }\end{array}$ & $\begin{array}{l}\% \text { residents who } \\
\text { received vaccines }\end{array}$ & $\begin{array}{l}\text { \% residents whose needs for help } \\
\text { with daily activities increased }\end{array}$ & $\begin{array}{l}\text { \% residents who received medication } \\
\text { (antipsychotic, hypnotic, and anti-anxiety) }\end{array}$ & $\begin{array}{l}\% \text { residents with a urinary } \\
\text { tract infection }\end{array}$ & $\begin{array}{l}\% \text { residents with } \\
\text { pressure ulcers }\end{array}$ & $\begin{array}{l}\text { \% residents with } \\
\text { depressive symptoms }\end{array}$ \\
\hline
\end{tabular}

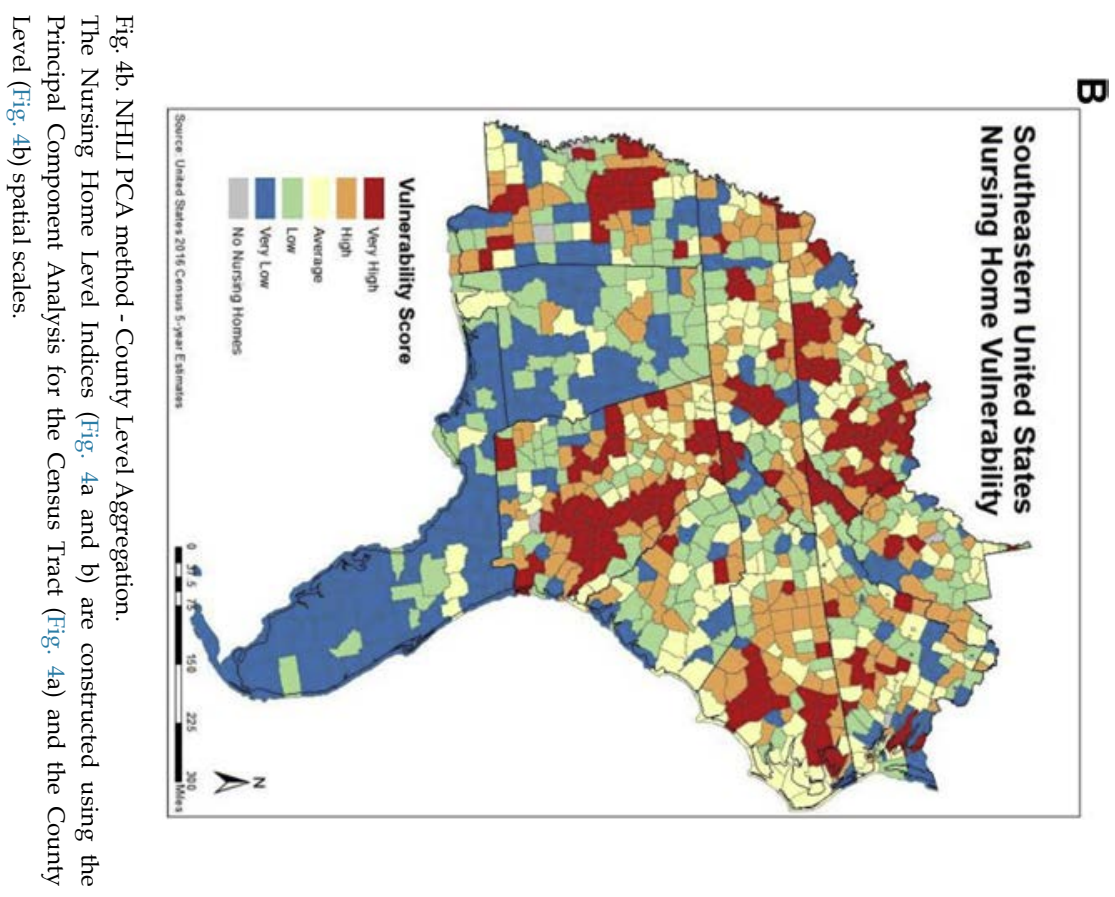

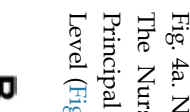

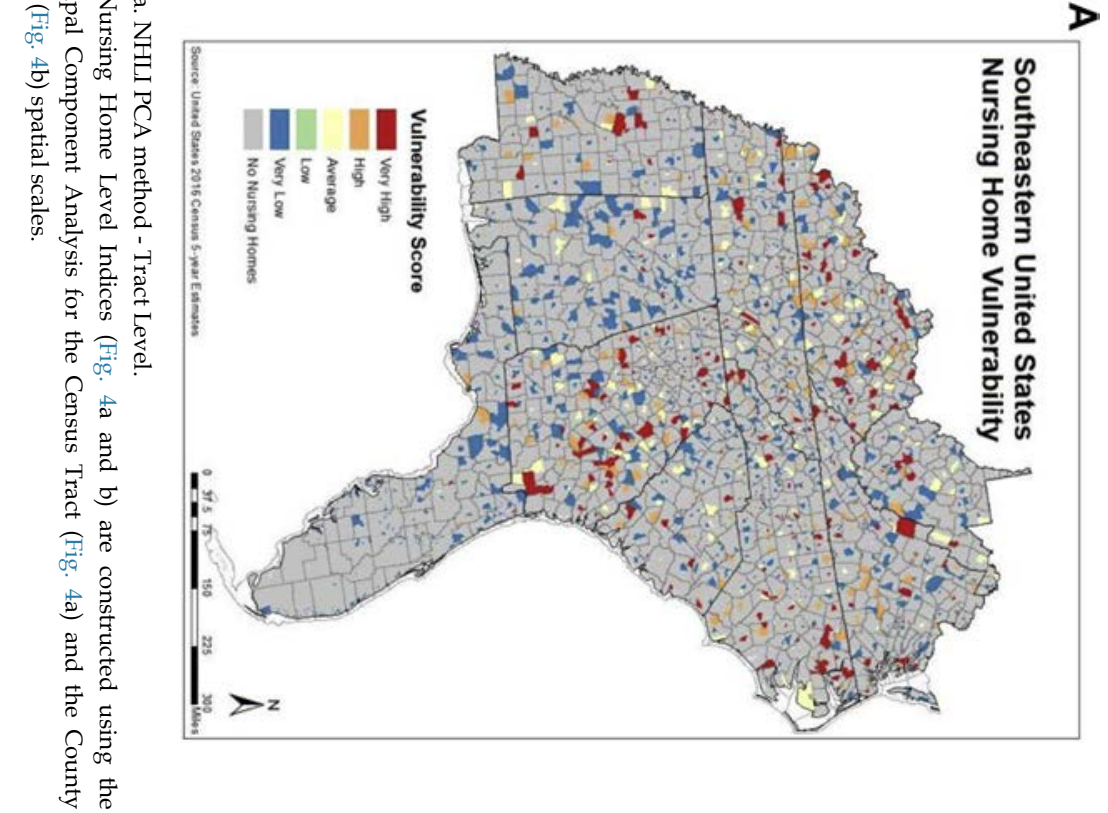




\begin{tabular}{|c|c|c|}
\hline Variable Name & Average Rank & Weight \\
\hline Percentage of long-stay residents whose need for help with daily activities has increased & 7.6 & $9.66 \%$ \\
\hline Percentage of long-stay residents who self-report moderate to severe pain & 5.2 & $6.61 \%$ \\
\hline Percentage of high risk long-stay residents with pressure ulcers & 6.4 & $8.14 \%$ \\
\hline Percentage of long-stay residents who lose too much weight & 5.4 & $6.87 \%$ \\
\hline Percentage of low risk long-stay residents who lose control of their bowels or bladder & 5 & $6.36 \%$ \\
\hline Percentage of long-stay residents with a catheter inserted and left in their bladder & 5.2 & $6.61 \%$ \\
\hline Percentage of long-stay residents with a urinary tract infection & 4.4 & $5.59 \%$ \\
\hline Percentage of long-stay residents who have depressive symptoms & 6 & $7.63 \%$ \\
\hline Percentage of long-stay residents who were physically restrained & 4.8 & $6.10 \%$ \\
\hline Percentage of long-stay residents experiencing one or more falls with major injury & 6 & $7.63 \%$ \\
\hline Percentage of long-stay residents who received appropriate vaccines & 3.2 & $4.07 \%$ \\
\hline Percentage of long-stay residents who received appropriate medication & 6.2 & $7.88 \%$ \\
\hline Percentage of long-stay residents whose ability to move independently worsened & 7 & $8.90 \%$ \\
\hline Staffing (CNA, LPN, RN, Total Staff) & 4.5 & $5.66 \%$ \\
\hline Organization type (For-Profit, Non-Profit, Government) & 1.8 & $2.29 \%$ \\
\hline
\end{tabular}

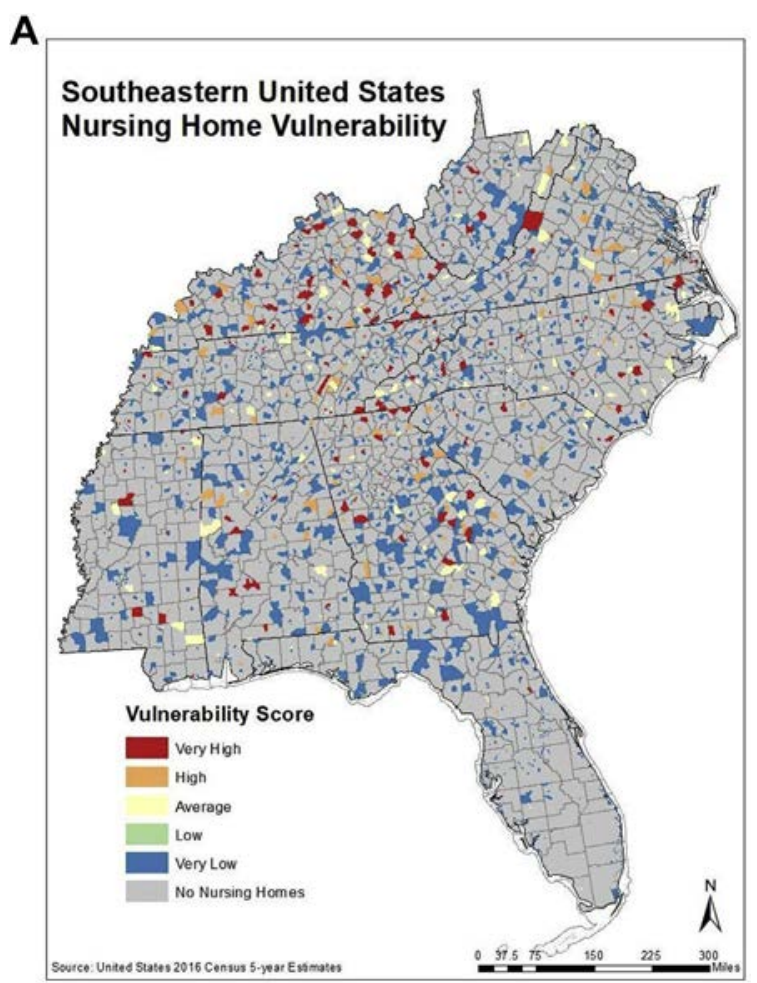

Fig. 5a. NHLI AHP method - Tract Level.

The Nursing Home Level Indices (Fig. 5a and b) are constructed using the Analytical Hierarchy Process for the Census Tract (Fig. 5a) and the County Level (Fig. 5b) spatial scales.

required to complete a risk assessment using an all-hazards approach that focuses on their capacities and capabilities. Included in the risk assessment is an understanding of the vulnerabilities attributable to place including natural hazard risks, and community-based risks and vulnerabilities, which allows for improved planning, preparedness, mitigation, response and recovery [24].

The clusters throughout the study area that were identified as the most vulnerable for the MNHVI are predominantly attributable to their geographic location along the coastline, which is visually evident through the HLI. This finding is not surprising and confirms the notion that geographic location contributes to, and often drives, vulnerability. However, there are cases when the HLI and geographic location are not the driving factor for vulnerability classification. Large inland cities (i.e., Atlanta, Charlotte, and Nashville, U.S.) have higher rates of vulnerability clustering than surrounding regions. These inland city

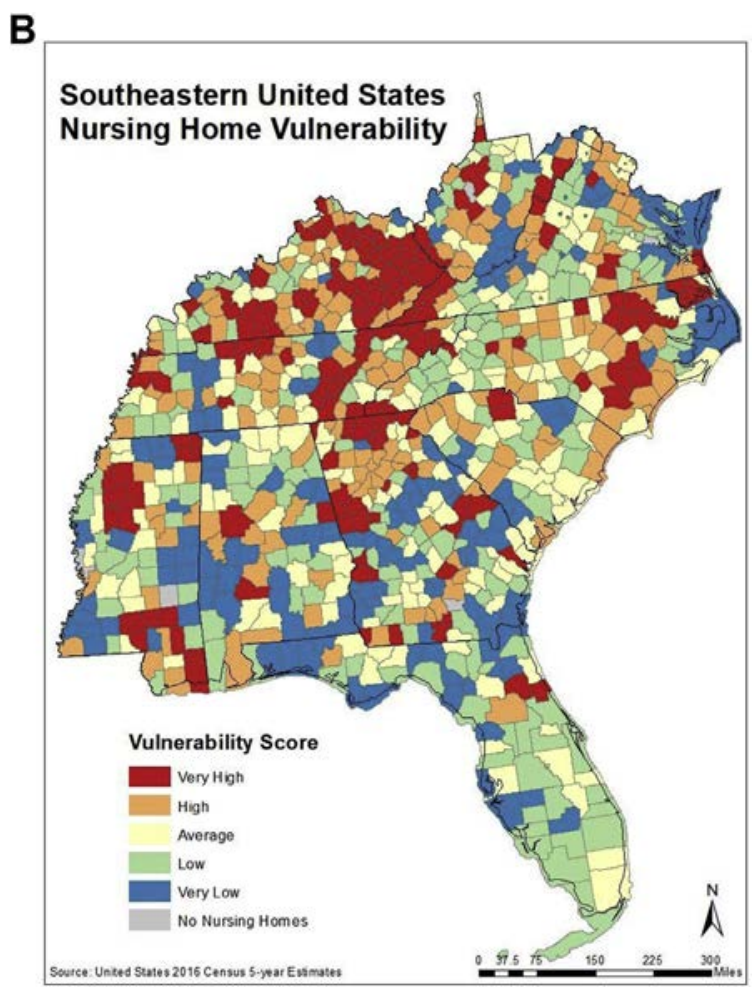

Fig. 5b. NHLI AHP method - County Level Aggregation.

The Nursing Home Level Indices (Fig. 5a and b) are constructed using the Analytical Hierarchy Process for the Census Tract (Fig. 5a) and the County Level (Fig. 5b) spatial scales.

vulnerability clusters are predominantly attributable to CLI scores which reveal the importance of identifying relative financial and social poverty as a driving force of community vulnerability. Emergency management personnel can use these CLI scores to identify pockets of vulnerability that are associated with community demographics and allocate resources to assist these communities and the nursing homes therein.

NHLI scores are often the driving factor for high MNHVI scores in rural/high poverty areas such as, Clay, Owsley, and Leslie counties in Kentucky, U.S., which tend to have correspondingly high CLI scores. Vulnerability that is attributable to either community or NHLI vulnerability requires officials within these locations to prepare for disasters using organizational factors and community sensitivity. Nursing homes located in these regions should evaluate vulnerability using organizational factors (resident acuity/change in status, quality of care metrics, 


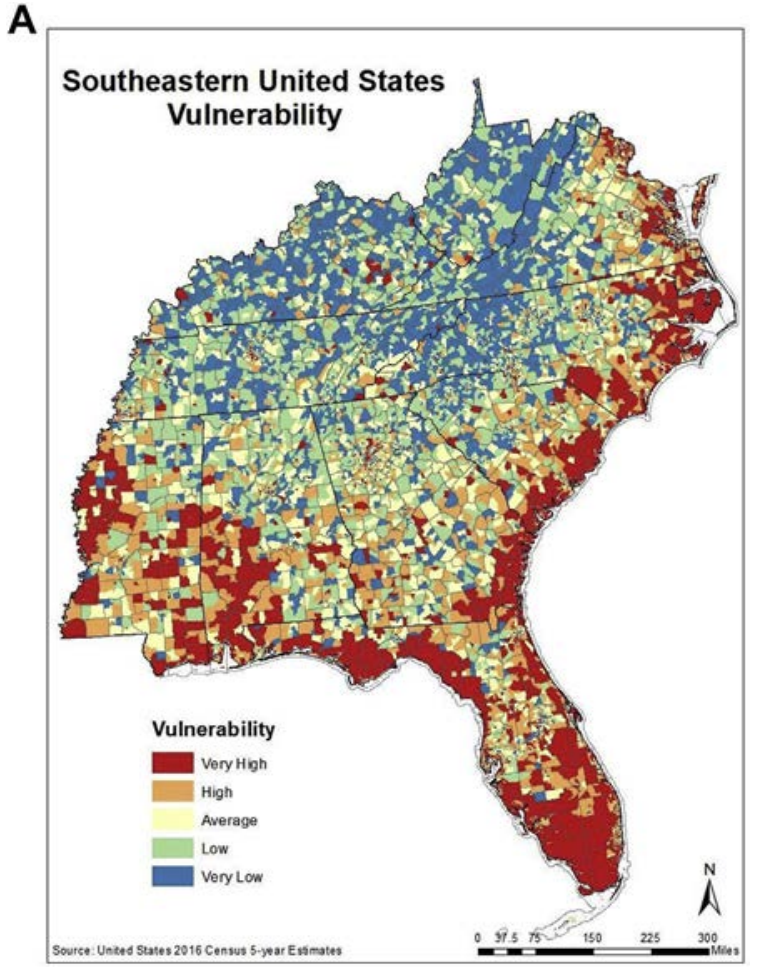

Fig. 6a. MNHVI - tract level.

The Multivariate Nursing Home Level Indices (Fig. 6a and b) are constructed using the equal weights methodology for the Census Tract (Fig. 6a) and the County Level (Fig. 6b) spatial scales.

B

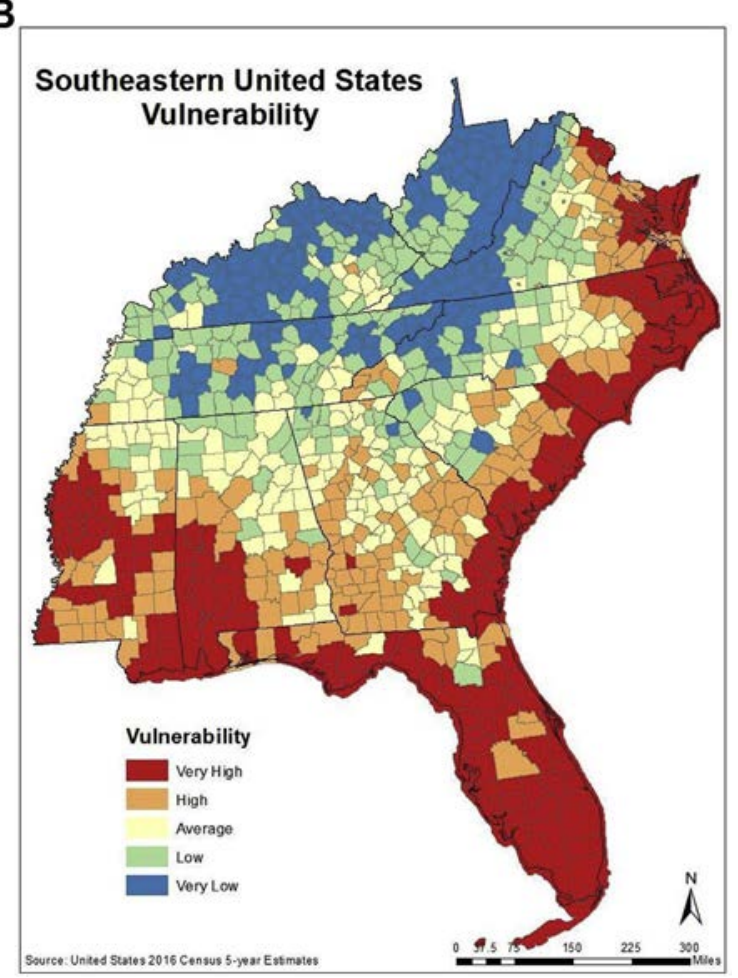

Fig. 6b. MNHVI - county level aggregation.

The Multivariate Nursing Home Level Indices (Fig. 6a and b) are constructed using the equal weights methodology for the Census Tract (Fig. 6a) and the County Level (Fig. 6b) spatial scales. and staffing) and community sensitivity, as well as understand their natural hazard exposure. Clusters of high NHLI vulnerability are associated with nursing home facility demographic similarities across census tracts and counties. Therefore, nursing homes located within highly vulnerable NHLI tracts and counties are more likely to house residents with limited, or reduced, mobility than nursing home facilities within low vulnerable NHLI areas. The identification of these counties or tracts with higher NHLI vulnerability allows for more accurate discussions between nursing home administrators, emergency management personnel, family members, and regulators related to evacuation and shelter-in-place decisions.

The MNHVI, which is the additive combination of vulnerability identified through the HLI, CLI, and NHLI, is designed to help build knowledge pertaining to nursing home vulnerability with the goal of helping improve individual nursing facility risk assessment and annual emergency plan updates. The additive nature of this index displays the majority of vulnerability along the coastlines where HLI values are most impactful. Outliers of high or low vulnerability within the MNHVI are due to extreme high or low values from the CLI or NHLI (e.g. Williamson County, TN, U.S. and Alachua County, FL, U.S.). The impact that the HLI has on the MNHVI may support the hypothesis that geographic location is highly impactful on nursing home facility vulnerability.

The mapped outputs from the MNHVI can provide facilities an easily distributable form of visual and quantitative information to share with emergency management agencies, family members or representatives of residents in nursing homes [50]. While previous models of vulnerability identification have been constructed, it is to the knowledge of the researchers that there has never been an index constructed at this large of a scale, using a natural hazards approach, that can be used specifically for individual nursing home facilities risk assessments and emergency plans for responding to disasters.

Prior to the creation of the MNHVI, Cutters SoVI (Shirley et al., 2012) and Morath and Hames et al.s MedVI [12,51] have been used to identify clusters of vulnerability for older adults. Neither of these indices were specific to nursing home facilities and therefore could not be used to confidently improve risk assessments. The SoVI is able to identify geographies of social vulnerability at both the national and sub-national level. However, social vulnerability is relative and was determined to be too coarse of an identifier for nursing facility vulnerability, especially under the natural hazards approach, which is why the inclusion of the HLI and NHLI were pertinent for this analysis. The MedVI has been used to identify socially and medically vulnerable geographies for non-institutionalized older adult populations at the subcounty level for several counties within Florida [12]. Yet the MedVI is not specific to nursing home populations and fails to include the frequency of natural hazards.

The MNHVI created in this study adds to the previous knowledge created by the SoVI and the MedVI. The SoVI methodology is incorporated as one of the sub-indices of the MNHVI to capture community vulnerability. Nursing home residents are inherently medically vulnerable and therefore the MedVI model was not incorporated into the MNHVI, however the variables associated with medical and resident vulnerability were evaluated by experts and captured through the NHLI sub-index. The MNHVI also incorporates vulnerability attributable to frequency and likelihood of natural hazard occurrences through the HLI sub-index. The identification of these core components (HLI, CLI, and NHLI) provides further insight into which community, hazard, and nursing home related variables have the largest impact on vulnerability throughout the study area.

The specificity of this index, relating to the older adult and nursing home facilities, enables necessary personnel to visualize vulnerability across the study region for a demographic that has historically been disproportionately impacted by natural hazards [7,10,31]. As the older adult population $(65+$ years) is expected to double from 43.1 million in 2012 to 83.7 million in 2050, and the oldest adult population 
$(85+$ years $)$ is expected to triple from 5.8 million in 2012 to 17.9 million in 2050 [52], and is expected to account for $20 \%$ of the American population by 2040 [31], the knowledge of vulnerable clustering of this demographic is becoming increasingly important. Therefore, identifying clusters of vulnerability can guide policy development, resource allocation, and local and organizational planning.

Specific examples of potential resources allocation may include, but are not limited to, appropriation of emergency transportation vehicles in vulnerable locations, and providing additional, or back-up, fuel for generators to facilities that are more likely to experience poweroutages. For disasters, which are projected to have long-term impacts and result in the potential prolonged displacement of certain residents, it is also important for emergency managers and facility administrators to have a plan for providing additional food and water for these residents. Emergency management personnel must determine facilities that need to be evacuated first, and the identification of vulnerable clusters can provide additional justification for timely evacuation of the most at-risk residents and the determination of the most appropriate location for these residents to be evacuated to Refs. [53-55].

The methods implemented in this study can be used by those who provide services to older adults in several ways. The inductive-hierarchical model that is employed illuminates not only which facilities house residents which are, comparatively, more vulnerable, but which vulnerable facilities are geographically vulnerable, as well. The results of this study can assist administrators in their risk assessment and planning, development of policies and procedures, communication plan, and training and testing to comply with the newly promulgated emergency preparedness regulations in the United States (Medicare and Medicaid Programs; Emergency Preparedness Requirements for Medicare and Medicaid Participating Providers and Suppliers; Final Rule, n.d.). By pinpointing census tracts and counties that are more atrisk, additional preventative measures and proactive strategies (i.e., policies and procedures to address identified vulnerabilities, training of staff on these procedures), along with increased collaboration with other critical infrastructure organizations (i.e., police, ambulance, fire, etc.) can occur [22]. Vulnerability of older adults to natural disasters and evacuations does not end when the storm is over as stressful situations can worsen existing physical and cognitive conditions [16]. By identifying facility level vulnerability, steps can be made to potentially lessen post-disaster morbidity, mortality, and post-traumatic stress to residents [25,31].

While the MNHVI does incorporate similar methods to traditional social vulnerability indices, the MNHVI is constructed using an idiosyncratic, triangulated, inductive-hierarchical approach. The incorporation of expert rankings, dictated by existing organizational theory, (e.g. Refs. [15,16,44,45] through AHP methodology, is expected to alter the uncertainty within the MNHVI. Previous research has identified the necessity to validate vulnerability indices, or at the very least to quantify and state uncertainty associated with outputs [30]. It is an understood limitation of this study that the potential uncertainty within this index could not be quantified.

Several accepted limitations are included within this study. First, there are variables which were not incorporated into each of the subindices, which have been incorporated into other vulnerability indices (e.g., wildfire, railways, etc.) [26]; McLaughlin et al., 2002). The variables chosen for the HLI do have a coastal bias, which results in higher coastal vulnerability for the MNHVI and HLI. In future studies, vulnerability indices would benefit from incorporating additional variables (i.e., the wildland-urban interface (WUI) as a proxy for wildfire risk, and FIRMS for inland and small stream flooding vulnerability). For this study, however, it was determined that hazards predominately experienced along the coast of the southeastern United States, especially those related to hurricanes and flooding, were of the utmost importance for older adult vulnerability $[19,54]$.

Additional variables for the NHLI and CLI could also be incorporated. Variables directly associated with nursing home vulnerability, within the contents of this study, are relatively unexplored and require further analysis. These variables could include, but are not limited to, analysis of road density and access to transportation networks, proximity to rail lines and power plants, and more detailed resident acuity data [54]. incorporated interviews with facility administrators who were impacted by storms. While unique experiences detailed in interviews are not replicable, we believe that the variables chosen for the CLI, HLI, and NHLI and the MNHVI provide a more robust picture which can be used for pre-event planning and future vulnerability research focused on nursing home residents.

Future research expanding the use of geospatial analysis with other facility and resident level data sets should be considered. Analysis using nursing home specific information can provide administrators, local emergency management agencies and other ESF-8 (FEMAs Emergency Support Function \#8 - Public Health and Medical Services) responders with information at a granular level that is more useful and applicable to their preparation and response needs. Potential future directions implementing these geospatial statistics and technology can produce vulnerability scores at a smaller, more specialized scale as well as confidence intervals around vulnerability scores. Employing these innovative computational and statistical strategies will allow for mapping at a finer scale along with enhanced policy and risk assessment decisions at a variety of emergency management levels.

\section{Acknowledgments}

The researchers thank Lauren Anderson who contributed to data collection and statistical analysis. This project was made possible by the University Research Council and the Sustaining Collaborative Opportunities for Research and Education (SCORE) initiative.

\section{References}

[1] 2018-2022 strategic plan helping people together (n.d), https:/ / www.fema.gov / strategic-plan, Accessed date: 17 August 2018.

[2] Billion-dollar weather and climate disasters, Table of Events. Noaa National Centers for Environmental Information (n.d.), https:/ / www.ncdc.noaa.gov/billions/events / US/2017, Accessed date: 17 August 2018.

[3] Medicare and medicaid programs, Emergency Preparedness Requirements for Medicare and Medicaid Participating Providers and Suppliers; Final Rule (n.d.), https://www.gpo.gov/fdsys/pkg/FR-2016-09-16/pdf/2016-21404.pdf , Accessed date: 17 August 2018.

[4] Flood insurance manual, Effective October 1, 2009 (n.d.), https:/ / www.fema.gov/ flood-insurance-manual-effective-october-1-2009 , Accessed date: 17 August 2018

[5] J. Chakraborty, G.A. Tobin, B.E. Montz, Population evacuation: assessing spatial variability in geophysical risk and social vulnerability to natural hazards, Nat. Hazards Rev. 6 (1) (2005) 23-33.

[6] S.L. Cutter, C.T. Emrich, Moral hazard, social catastrophe: the changing face of vulnerability along the hurricane coasts, Ann. Am. Acad. Pol. Soc. Sci. 604 (1) (2006) 102-112.

[7] S.L. Cutter, C. Finch, Temporal and spatial changes in social vulnerability to natural hazards, Proc. Natl. Acad. Sci. Unit. States Am. 105 (7) (2008) 2301-2306.

[8] B.E. Flanagan, E.W. Gregory, E.J. Hallisey, J.L. Heitgerd, B. Lewis, A social vulnerability index for disaster management, J. Homel. Secur. Emerg. Manag. 8 (1) (2011).

[9] B.E. Montz, G.A. Tobin, Natural hazards: an evolving tradition in applied geography, Appl. Geogr. 31 (1) (2011) 1-4.

[10] J. Brunkard, G. Namulanda, R. Ratard, Hurricane katrina deaths, Louisiana, 2005, Disaster Med. Public Health Prep. 2 (4) (2008) 215-223.

[11] D. Dosa, Z. Feng, K. Hyer, L.M. Brown, K. Thomas, V. Mor, Effects of hurricane katrina on nursing facility resident mortality, hospitalization, and functional decline, Disaster Med. Public Health Prep. 4 (S1) (2010) S28-S32.

[12] E. Hames, J. Stoler, C.T. Emrich, S. Tewary, N. Pandya, A gis approach to identifying socially and medically vulnerable older adult populations in south Florida, Gerontol. 57 (6) (2016) 1133-1141.

[13] L. Brown, M. Rothman, F. Norris, Issues in mental health for older adults during disasters, Generations 31 (4) (2007) 25-30.

[14] S.B. Laditka, J.N. Laditka, S. Xirasagar, C.B. Cornman, C.B. Davis, J.V. Richter, Protecting nursing home residents during emergencies or disasters: an exploratory study from South Carolina, Prehospital Disaster Med. 22 (1) (2007) 42-48.

[15] S.B. Laditka, J.N. Laditka, S. Xirasagar, C.B. Cornman, C.B. Davis, J.V. Richter, Providing shelter to nursing home evacuees in disasters: lessons from hurricane katrina, Am. J. Public Health 98 (7) (2008) 1288-1293.

[16] D. Dosa, K. Hyer, K. Thomas, S. Swaminathan, Z. Feng, L. Brown, V. Mor, To evacuate or shelter in place: implications of universal hurricane evacuation policies 
on nursing home residents, J. Am. Med. Dir. Assoc. 13 (2) (2012) 190-e1.

[17] W.N. Adger, T.P. Hughes, C. Folke, S.R. Carpenter, J. Rockström, Social-ecological resilience to coastal disasters, Science 309 (5737) (2005) 1036-1039.

[18] M.K. Andrew, A.B. Mitnitski, K. Rockwood, Social vulnerability, frailty and mortality in elderly people, PLoS One 3 (5) (2008) e2232.

[19] C.T. Emrich, S.L. Cutter, Social vulnerability to climate sensitive hazards in the southern United States, Weather, Climate, and Society 3 (3) (2011) 193-208.

[20] J. Evans, Mapping the vulnerability of older persons to disasters, Int. J. Older People Nurs. 5 (1) (2010) 63-70.

[21] A. Haines, R.S. Kovats, D. Campbell-Lendrum, C. Corvala'n, Climate change and human health: impacts, vulnerability and public health, Publ. Health 120 (7) (2006) $585-596$.

[22] J. Perdikaris, B. Gharabaghi, E. McBean, A methodology for undertaking vulnerability assessments of flood susceptible communities, Internationaljournal of safety and security engineering 1 (2) (2011) 126-146.

[23] G.A. Tobin, B.E. Montz, Natural hazards and technology: vulnerability, risk, and community response in hazardous environments, Geography and Technology, Springer, 2004, pp. 547-570.

[24] K. Hyer, L.M. Brown, A. Berman, L. Polivka-West, Establishing and refining hurricane response systems for long-term care facilities, Health Aff. 25 (5) (2006) w407w411.

[25] S.B. Laditka, J.N. Laditka, C.B. Cornman, C.B. Davis, J.V. Richter, Resilience and challenges among staff of gulf coast nursing homes sheltering frail evacuees following hurricane katrina, 2005: implications for planning and training, Prehospital Disaster Med. 24 (1) (2009) 54-62.

[26] G. Wigtil, R.B. Hammer, J.D. Kline, M.H. Mockrin, S.I. Stewart, D. Roper, V.C. Radeloff, Places where wildfire potential and social vulnerability coincide in the coterminous United States, Int. J. Wildland Fire 25 (8) (2016) 896-908.

[27] L.M. Berrouet, J. Machado, C. Villegas-Palacio, Vulnerability of socioecological systems: a conceptual framework, Ecol. Indicat. 84 (2018) 632-647.

[28] P. McLaughlin, T. Dietz, Structure, agency and environment: toward an integrated perspective on vulnerability, Glob. Environ. Chang. 18 (1) (2008) 99-111.

[29] T.T. Nguyen, J. Bonetti, K. Rogers, C.D. Woodroffe, Indicator based assessment of climate-changeimpacts on coasts: a review of concepts, methodological approaches and vulnerability indices, Ocean Coast Manag. 123 (2016) 18-43.

[30] E. Tate, Social vulnerability indices: a comparative assessment using uncertainty and sensitivity analysis, Nat. Hazards 63 (2) (2012) 325-347.

[31] J.L. Gamble, B.J. Hurley, P.A. Schultz, W.S. Jaglom, N. Krishnan, M. Harris, Climate change and older americans: state of the science, Environ. Health Perspect. 121 (1) (2012) 15-22.

[32] L. Rygel, D. Osullivan, B. Yarnal, A method for constructing a social vulnerability index: an application to hurricane storm surges in a developed country, Mitig. Adapt. Strategies Glob. Change 11 (3) (2006) 741-764.

[33] M.C.Schmidtlein, R.C. Deutsch, W.W. Piegorsch, S.L. Cutter, A sensitivity analysis of the social vulnerability index, Risk Anal.: Int. J. 28 (4) (2008) 1099-1114.

[34] Environmental Systems Research Institute (ESRI), ArcGIS Desktop Release 10.6. Redlands, CA, (2018).

[35] S.L. Cutter, B.J. Boruff, W.L. Shirley, Social vulnerability to environmental hazards, Soc. Sci. Q. 84 (2) (2003) 242-261.

[36] C. Harrington, H. Carrillo, B.W. Blank, Nursing Facilities, Staffing, Residents and Facility Deficiencies, 2001 through 2007, Department of Social and Behavioral Sciences, University of California, San Francisco, CA, 2008http:/ / www.canhr.org/ reports/2008/OSCAR.pdf.
[37] H. Kim, C. Harrington, W.H. Greene, Registered nurse staffing mix and quality of care in nursing homes: a longitudinal analysis, Gerontol. 49 (2009) 81-90, https:/ / doi.org/10.1093/geront/gnp014.

[38] K. Hyer, K. Thomas, L. Branch, J. Harman, C. Johnson, R. Weech-Maldonado, The influence of nurse staffing levels on quality of care in nursing homes, Gerontol. 51 (5) (2011) 610-616.

[39] B. Williams, A. Onsman, T. Brown, Exploratory factor analysis: a five-step guide for novices, Australasian Journal of Paramedicine 8 (3) (2010).

[40] H.F. Kaiser, The application of electronic computers to factor analysis, Educ. Psychol. Meas. 20 (1) (1960) 141-151.

[41] J.A. Alonso, M.T. Lamata, Consistency in the analytic hierarchy process: a new approach, Int. J. Uncertain. Fuzziness Knowledge-Based Syst. 14 (04) (2006) 445-459.

[42] B. Feizizadeh, S. Kienberger, Spatially explicit sensitivity and uncertainty analysis for multicriteria-based vulnerability assessment, J. Environ. Plan. Manag. 60 (11) (2017) 2013-2035.

[43] Analytic hierarchy process (ahp), (n.d), http://people.revoledu.com/kardi/ tutorial/AHP/, Accessed date: 17 August 2018.

[44] J.N. Morris, B.E. Fries, D.R. Mehr, C. Hawes, C. Phillips, V. Mor, L.A. Lipsitz, Mds cognitive performance scale, J. Gerontol. 49 (4) (1994) M174-M182.

[45] J.N. Morris, B.E. Fries, S.A. Morris, Scaling adls within the mds, J. Gerontol.: Series A 54 (11) (1999) M546-M553.

[46] E. Tate, Uncertainty analysis for a social vulnerability index, Ann. Assoc. Am. Geogr. 103 (3) (2013) 526-543.

[47] L.A. Bakkensen, R.O. Mendelsohn, Risk and adaptation: evidence from global hurricane damages and fatalities, Journal of the Association of Environmental and Resource Economists 3 (3) (2016) 555-587.

[48] Y. Zhou, N. Li, W. Wu, J. Wu, P. Shi, Local spatial and temporal factors influencing population and societal vulnerability to natural disasters, Risk Anal. 34 (4) (2014) 614-639.

[49] Florida nursing home death toll reaches 14, (n.d), https://www.cnn.com/2017/10/ 09/health/florida-irma-nursing-home-deaths-wife/index.html , Accessed date: 17 August 2018.

[50] Understanding the emergency preparedness final rule and training and testing requirements, (n.d), https://www.cms.gov/Outreach-and-Education/Outreach/NPC/ National-Provider-Calls-and- Events-Items / 2017-04-27-Emergency-Preparedness. html , Accessed date: 17 August 2018.

[51] D.P. Morath, Social Vulnerability and Public Health: Developing a Metric for Medical Emergency Management in Florida, (2010) (Master's thesis). Retrieved from: https://scholarcommons.sc.edu/etd/1298, Accessed date: 17 August 2018.

[52] S. Malik, D.C. Lee, K.M. Doran, C.R. Grudzen, J. Worthing, I. Portelli, ... S.W. Smith Vulnerability of older adults in disasters: emergency department utilization by geriatric patients after hurricane sandy, Disaster Med. Public Health Prep. 12 (2) (2018) 184-193.

[53] W.P. Mangum, J.I. Kosberg, P. McDonald, Hurricane Elena and Pinellas County, Florida: some lessons learned from the largest evacuation of nursing home patients in history, Gerontol. 29 (3) (1989) 388-392.

[54] B.M. Vogt, Issues in nursing home evacuations, Int. J. Mass Emergencies Disasters 9 (2) (1991) 247-265.

[55] N. Wilson, Hurricane katrina: unequal opportunity disaster, Public Policy and Aging Report 16 (2) (2006) 8-13.

[56] H.-M. Füssel, Vulnerability: a generally applicable conceptual framework for climate change research, Glob. Environ. Chang. 17 (2) (2007) 155-167. 